\title{
Socio-Financial Disruption - Key Tips to Manage and Ensure the Business Continuity
}

\begin{abstract}
When any disaster, manmade or natural hits the business operations, leave unnoticed the usual operations, threatening the business, involving disruption of activities or destruction of property, resources, lives, etc, then the Organization is faced a crisis. Risk is outside everywhere, and it may impact us more or less. Disaster may have many faces and even we are aware and think that we are prepared to deal with it, somehow, we find ourselves not ready. The study was conducted on two different types of institutions, in a multicultural environment. The article aims to present possible key tips to manage and ensure business continuity by strictly evaluating the core values and strategic prioritization, involving all employees and amending the organizational structure and culture. The research underlines that in case of disaster, improvements are not mandatory to be completely new or drastic in nature. The article concludes that putting the business on hold, closing, or staying at home is not a long-run solution, it will really affect the socio-financial the situation, at all levels, individual, institutional, governmental. The work paper emphasis that it is better to apply the rule of $5 \mathrm{Es}$, with the accent on strategic priorities and everyone's involvement through a clear operational plan. Businesses need to take a step back and assess the situation in a critical way, emphasize the core value, strategic priorities, and bring together all resources it can rely on, and more importantly, take care of the employees, they are the one can make the business rise again.
\end{abstract}

Keywords: Disaster management crisis management, Strategic priorities, Organizational behaviour, Business continuity.

DOI: $10.20448 / 807.6 .2 .87 .95$

Citation | Narcisa Roxana Mosteanu (2020). Socio-Financial Disruption - Key Tips to Manage and Ensure the Business Continuity. Global Journal of Social Sciences Studies, 6(2): 87-95.

Copyright: This work is licensed under a Creative Commons Attribution 3.0 License

Funding: This study received no specific financial support.

Competing Interests: The author declares that there are no conflicts of interests regarding the publication of this paper.

History: Received: 2 July 2020/ Revised: 5 August 2020/ Accepted: 26 August 2020/ Published: 14 September 2020

Publisher: Online Science Publishing 


\section{Highlights of this paper}

- The article aims to present possible key tips to manage and ensure business continuity by strictly evaluating the core values and strategic prioritization.

- Crisis management as a tool to help the business to survive and recover during and after a disaster.

\section{INTRODUCTION}

Management is an art of strategic planning, organizing, decision-making and leading a group of people by motivating and controlling all production resources of an organization in order to meet in an effective way the stakeholders' needs. In normal and peaceful times, this seems easy to achieve. However, when the environment's forces are changing dramatically, in the case of disaster, management is required to active and prompt interfere in order to avoid financial and social chaos.

The widespread of a virus that attracts as a security measure the lockdown of the borders of the country and remote the work from the office to home, or the temporary closure of some activities has the immediate consequence of the disaster risk. The beginning of the technical unemployment, the reduction of the production activity of goods and services, has an effect in the short term the closing or holding-on of the business that is not related to the supply of food and medical products or services, and, in the long term the increase of the governmental public expenses, the increase of the public debt and the application of drastic measures such as the reduction of the salary level, or, in the worst case, the rationalization of the food and access to public utilities. With the aim of avoiding this possible financial crisis and social chaos the present paper underlines the imperious necessity to keep the business ongoing. The article aims to present the possible key tips to manage the risk of dramatically environmental changes, focusing on things which are more important for the wealth of all stakeholders: people and cash, social and financial.

\section{METHOD}

\subsection{Research Methodology}

The working paper is an investigative study, centered on analytical procedures. This study was conducted on two different types of institutions: financial institutions, SMEs from different industries, and universities. Information was congregated through face-to-face interaction with representative people. The main question was: were you ready for a financial and social disruption? All interviewed representatives were asked the following questions: the existence of a risk management policy; exist and recovery business plan; awareness of employees about the business scenario in case of disaster and what are their responsibilities; and how they rebuild the trust and credibility with stakeholders. Based on this, the present paper is an essential and qualitative examination, which objects to identify the main changes that may occur during and after a disaster, and it presents the possible ways of improving the organizational culture approach in order to prevent and recover during the financial, economic, and social disruption.

\subsection{Terminology}

During the analyze part, the present article will use the following terminologies:

Risk Management. Risk management is a process that identifies loss exposures faced by an organization and select the most appropriate techniques for treating such exposures (Rejda \& McNamara, 2017).

Disaster. A disaster is a sudden, calamitous event that seriously disrupts the functioning of a community or society and causes human, material, and economic or environmental losses that exceed the community's or society's 
ability to cope using its own resources. Disaster denotes a low-probability but high-impact event that causes a large number of individuals to become ill or injured.

Risk of disaster. Risk of disaster is widely recognized as the consequence of the interaction between a hazard and the characteristics that make people and places vulnerable and exposed (Moşteanu, 2020a; UNISDR, 2015) as can be seen in Figure 1.

Risk of disaster $=$ Hazard $\mathrm{x}$ Exposure $\mathrm{x}$ Vulnerability

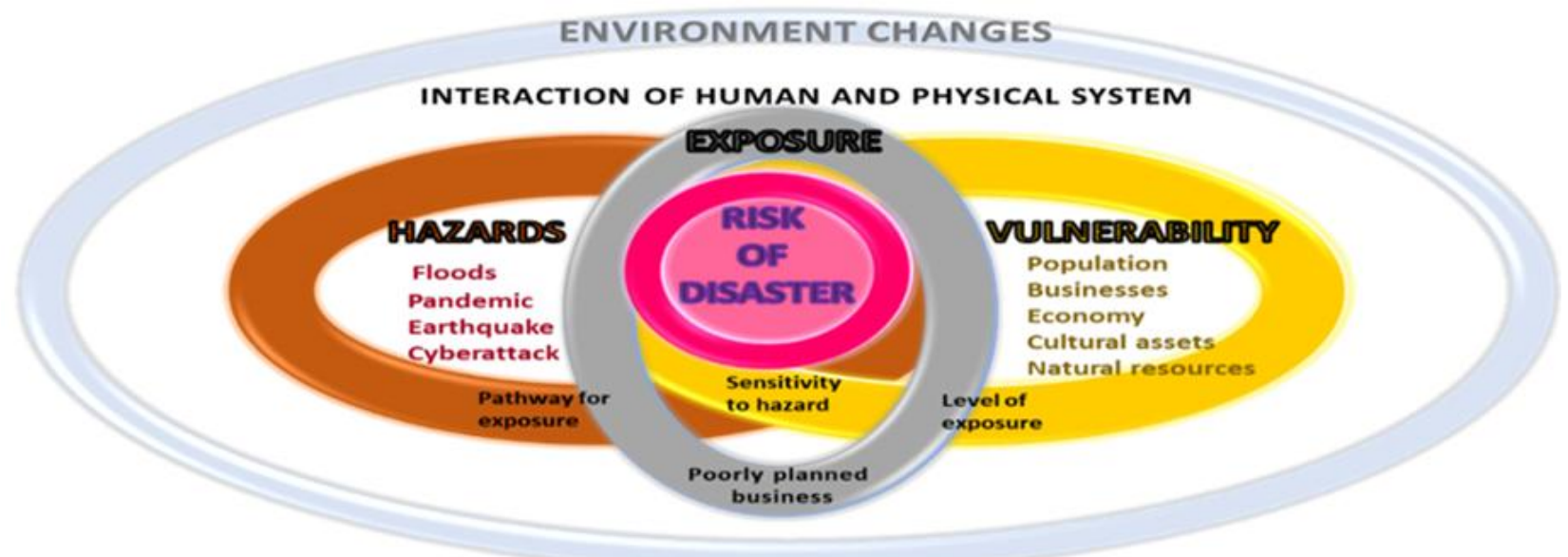

Figure-1. The relationship between hazard, risk, and vulnerability, when there is an interaction of a human and physical system. Source: Moşteanu (2020a).

Management of disaster. Management of disaster is a combined term encompassing all aspects of planning for and responding to disasters, including both pre-disaster and post-disaster plans. Management of disaster deals with the management of an organization's resources and responsibilities to control the risk and its impact (Moşteanu, 2020a). Crisis management is the process by which an organization deals with a disruptive and unexpected event that threatens to harm the organization or its stakeholders. Crisis management is also a part of Disaster management. When any disaster either man-made or natural strikes the business operations paralyzing the normal operations, threatening the business, involving destruction of property, resources, lives, etc., the organization is faced with a crisis. It is one matter that the Disaster recovery teams will start the action as per their plan and work towards getting the business back to its normalcy (Parachi, 2020). Organizational culture. Organizational culture as the set of shared values and norms that control organizational members' interactions with each other and with suppliers, customers, and other people outside the organization. If, an organization's structure is designed to achieve competitive advantage and promote stakeholder interests, the organization's culture can be used to increase organizational effectiveness (Jones, 2013; Smircich, 1983).

Strategy. An organization's strategy is a specific pattern of decisions and actions that managers take to use core competencies and values to achieve a competitive advantage and outperform competitors (Jones, 2013; Smircich, 1983). In our context, value is anything that helps the organization to mitigate the risk of disaster and to succeed to exit the disruption phase with minimum losses.

Organizational Environment. The organizational environment is the set of forces and conditions that operate beyond an organization's boundaries but affect its ability to acquire and use resources to create value (Jones, 2013).

Financial and Social disruption. Financial and social disruption is a situation wherein markets (regardless of industry) cease to function in a regular manner, typically characterized by rapid and large economic declines.

Core values. Core values are the rules and boundaries that define the organization's culture and personality. 


\section{LITERATURE REVIEW}

Disasters have dominated the news recently, and impose organizational decision making to re-focus, redesign their organizational culture and concentrate on their Disaster Recovery Plans and Business Continuity Plans, or even to reconsider their business's structure. After the disaster happened, normally all organizations and peoples want to get things back to normal as quickly as possible and to offer assistance to others who were and still might be affected. Regrettably, getting back to normal may not be a straightforward process and it may involve very different hazards than organizations and employees deal with on a day-to-day basis (Busick, 2014). A study conducted by The Risk Management Association (RMA) since 2006 about Pandemic Flu Disruption indicated that many institutions are preoccupated to prepare themselves for a possible pandemic. However, even the majority of them were aware that this disruption can last between three and nine months or longer and will face financial losses, only a few enrolled backup plans and begun training the personnel and test the emergency plans to ensure workplace transmission of risk and ensure business continuity. Here, the need to understand what risk, disaster or disruption mean, as well as what effects they have on our economic and social life.

Economists Rejda and McNamara (2017) have been defined risk in terms of uncertainty. Based on this concept, the risk is defined as uncertainty concerning the occurrence of a loss. In the literature, risk perception studies (Grothmann \& Reusswig, 2006; Lindell \& Perry, 2000; Slovic, 2000; Slovic., 1992) have surveyed a wide range of hazardous events that mainly consist of technical, environmental, epidemiological, daily, and natural hazards. The development of risk perception studies is mainly motivated by the examination that there are significant differences between experts' objective assessments of risk and laypersons' intuitive judgments of risk. Thus, understanding people's risk perception and its determining factors are essential for improving risk assessment and designing effective mitigation policies. Risk perception may be the first step of risk mitigation or adjustment of organizational structure and culture. And how we are precepting the risk? We are precepting when our health and wealth are affected (individually, institutionally, or at the macroeconomic level) (Moşteanu, 2020a).

A disaster is a circumstance that totally disrupts the ordinary ways of a community. It leads to economic, social, and environmental losses. Disaster may appear as a result of a hazard. A hazard is a situation where there is a threat to life, health, environment, or property. Generally, the hazard is very difficult to foreseen or prevent. Disasters, in a simple approach, are assimilated with external shocks. Disaster usually is associated with uncertainty. Therefore, the disaster risk results from the complex interaction between development processes that generate conditions of exposure, weakness, and hazard. Disaster risk is consequently considered as the combination of the severity and frequency of a hazard, the numbers of people and assets exposed to the hazard, and their vulnerability to damage (Grigsby, 2002). Disasters may trigger disastrous malfunctions in optical networks, as many other systems failures may occur in a disaster zone. Such failures could also be cascading. Generally, when a disaster occurs, initially a set of network elements may fail altogether, and then other crashes in various parts of the network may occur subsequently (e.g., due to a power outage after an earthquake, due to an epidemiologic, or a cyber-attack on one important public administration) (Dikbiyik, Tornatore, \& Mukherjee, 2014; Moşteanu., 2020b; Moşteanu \& Galea, 2020; Moşteanu 2020c; Moşteanu \& Faccia, 2020; UNISDR, 2015).

In order to exist from a financial, economic and social crisis, many researchers recommend calling for loans, considering that credit provides cash in a crisis and can allow firms to replace lost assets, increasing their earnings opportunities after a severe event (Collier \& Babich, 2019). Other researchers with whom we are sharing the same idea, recommend, together with a critical examination of all resource's preparation and implementation of a strategic prioritized plan. 


\section{ANALYZING AND RESULTS}

The business's continuity is linked directly with the capability to prevent and manage any risk, with the openness to changes (Moşteanu 2020d); (Moşteanu, 2020e). We cannot say that our life or our business operates $100 \%$ safe without any risk. And via risk, we understand any event which may expose us to certain danger, harm, or loss. The risk may expose one person, one company, one community, or more, the situation when we face a disaster. And one of the most dangerous is the risk of disaster. The experts describe a disaster as an event that causes more than 10 deaths, affects more than 100 people, or leads to an appeal for assistance by those affected (Bravata et al., 2004; Front Matter, 2007).

Disaster generally appears when hazards meet vulnerability (see Figure 1). In a normal environment (general or specific) there are risks that can affect your activity or socio-economic status and can be predicted (market risks, credit risk, liquidity risk, new technology risk), even they meet or not vulnerable parts of an organization, individuals, or community. When a hazard doesn't interact with the vulnerability, then there is no exposure to disaster or crisis. When there is an interaction between human and physical system (hazard meet the vulnerability) than economic activities and social life are exposed to a disaster. A hazard by itself is not a disaster. Once the hazard meets a vulnerable situation, then a disaster happens (Moşteanu, 2020a). Individuals, businesses, and the whole economy are exposed when they are unable to effectively predict, withstand, and recuperate from exposures. If they cannot recover, or they are not helped to recover, financial, economic, and social disruptions and poverty may appear. Poverty contributes to vulnerability, and we can enter into a spiral of national, regional, or even global disaster. When any disaster reaches the business effectiveness disabling the usual operations, jeopardizing the activity, involving destruction of resources and put employee's social status in danger, the organization is faced with a crisis.

Crisis management necessitates handling and enabling decision making, authorizing and providing resources (economic, personnel, technologies...), enabling coordination, support and taking adequate measures for enhancing security around the premises. More significantly, the emergencies team including senior management will require to timely and effective communication, deal with mass-media, insurance as well as with employees. It is the crisis team, as part of the Disaster Management Department, that takes the executive authority to make decisions, including financial decisions to ensure that the crisis is managed and recovery is underway without faults. Figure 2 presents the crisis management process and key actions which Disaster Management Department, including Crisis team, is better to have them in their view, without losing any time.

The crisis is not a time for the uninitiated, nor for learning, or reinventing things that should be known. Disaster has many faces; however, they are followed by disruptions and crises. And the financial and social crisis is not behaving differently, they are following the same pattern (Nathanial \& Van der Heyden, 2020). We have to learn from the past and be prepared for the present and future. Every organization's management is better to have a mechanism to assess the risk and respond pro-active in order to avoid a financial disruption or to conquer a social disaster. In this regard, the rule of $5 E$ (Engage, Explore, Explain, Execute, and Evaluate) is better to be verified, adapt, and apply where is appropriate.

The Explanation phase is more complex. This is the stage in which we address our core values, strategic priorities, and we know almost sure about which resources we can rely on. The involvement of all employees in the organizational activity is vital. This is the moment for team spirit, and it is important to get anyone in the organization on the same page. And, by getting on the same page means that all organization's employees are aware about that page. So, we need to create a common understanding policy, a concise vision strategy - the page - in order to let everyone to get on Harnish (2020). 
- Remain yourselves

- Trust your instinct and capabilities

- Don't agree with anything you do not understand

- Remain open to Feedback and Criticism

- Evaluate and reassess continuously

- Admit mistakes, keep learning, find ways of

improvements

- Prepare a recovery plan (for next quarter, year, or

multi-yearly)

- Adapt the organization culture to avoid a repetition

of a similar crisis

- Crisis is a call for method and leadership

- Let all employees know about your strategic plan (train them if it is necessary)

- Start implement your strategic plan

- Remind stakeholders of purpose and of the results to

be executed

- Execute what you have decided

- Show that the scenarios work and that the expected results are being realized

- Build trust and credibility with stakeholders based on objective measurement (KPI for each employee, or team)

- Show that you are resourced for contingencies

- Monitor daily your Critical Resources

- Communicate the progress on daily basis (morning business report)

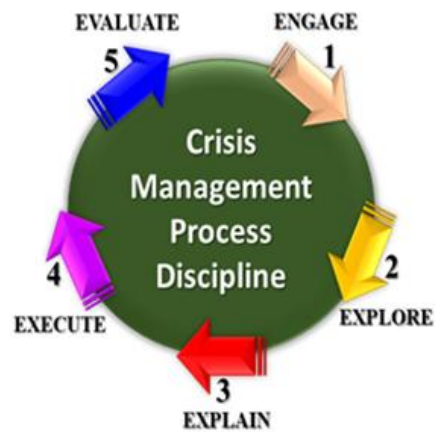

- Financial Impact. Time is your enemy

- Maintain a basis of business and Revise your strategy

- Prepare one page concise vision strategy

- The vital decision: stay or leave?

- What is your strategic priorities?

- Define vour core values and mission

- Clearly communicate your purpose

- Present one or multiple scenarios that will work and thei possible impact

- Prepare backup for each scenario. Prepare strategic pla Figure-2. Crisis management process discipline.

Source: adaptation based on Nathanial and Van der Heyden (2020)
- Recall the last financial and social disnuption

- What was the lesson learned? What others did to survive? What did you do?

- Setting the crisis correctly

- Engage people / employees early (train

the employees for emergency cases)

- Adapt and Present your own method to mitigate the crisis
- Segmentation and Sorting information

- What is the current situation? External and internal

- How you got here is not the way to get out?

- Understand people's motivation

- Keep the objective and independent

analyse and thinking

- Identify the team which can fight the crisis, and another team able to look ahead at exit (recovering stage)

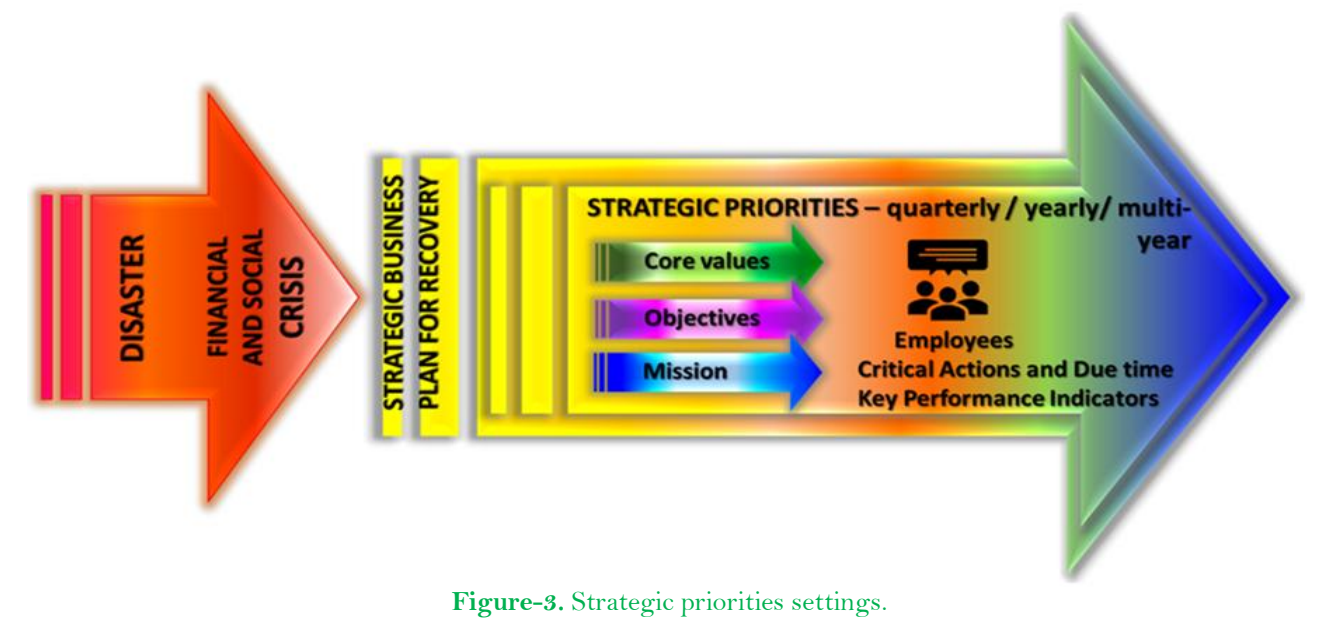

Figure-3. Strategic priorities settings

Functioning to manage financially and socially crisis to ensure the business continuity, the organization has to ensure that it has a clear vision and strategy, for the short, medium, and long run. A quick clear revision of the business plan is required in line to certify which are the core value, objectives, mission included inside the strategic priorities. This will allow all employees to participate actively in rebuilding or ensuring the continuity of the business, having clear actions, and due time for their achievement Figure 3.

Strategic priorities will help the organization to optimally allocate (financial) resources, activity by activity, focusing for present and next quarter, year, and on a multi-year plan. Having a clear image of your actions plan, shared with all employees, will let everyone know where and when to focus; they will be able to prepare their own daily activity plan. The success of the institution's activity continuity through financial and social crisis depends on the business' strategic priorities and employees. According to the Growth Institute (Harnish, 2020 the one-page strategic plan should start from core values, mission, and objective, which have to be acknowledged by all employees, in this way they will understand better their objectives and activities, helping them to complete timely the KPY.

Keeping the core values in mind, during crisis times, organizational culture and behavior have to adapt to the strategic prioritized emergency business plan and to be strictly obeyed. Organizational design is about how and why various resources are chosen. Organizational structure and culture are the means the organization is using to 
achieve its primary objectives. Organizational culture implies a system of shared values and is the result of its design and the principles behind its operations. The organizational culture symbolizes the set of shared values and norms that control organizational members' interactions with each other and with suppliers, customers, and other people outside the organization. Values are general criteria, standards, or guiding principles that people use to determine which types of behaviors, events, situations, and outcomes are desirable or undesirable. These values have a strong influence on employees' behavior as well as organizational effectiveness.

The ability of an organization's culture to adapt to the environments changes and to motivate employees, save the organizational resource, keep it on the market and increase its efficiency is straight linked to the way in which members absorb the organization's values and understand the importance of their active implication and dedication. Now, coming back to our strategic priorities and its implementation by the crisis management team, a new set of rules is better to be implemented for all employees. Employees are better to be trained about what does it mean and how to react in case of disaster, how to react in case their activity will he shifted from office to work-from-home (online). In this regard, organizational culture is better to adapt itself, and principles of risk prevention, and how to behave in case of a disaster have to be part of one internal pre-disaster employees' policy. Employee protection is very important. Employees are the one which will ensure the business continuity and will help the whole organization to pass through the disaster phase and participate in its recovery and to become effective and profitable again. In case there are new skills and qualifications are required, the organization would be better to train the employees earlier (Moşteanu, 2020a).

\section{CONCLUSIONS}

In case of disaster, improvements are not mandatory to be completely new or drastic in nature. They drive growth and help address social challenges and can contribute to the mitigation of climate change, the advancement of sustainable development, and the promotion of social cohesion (Gault, 2018). To tackle those issues, organizational structure and culture's changes are better to be cost-effective, endure employees' safeties, decrease losses, and safeguard a successful recovery and rehabilitation (Izumi, Shaw, Djalante, Ishiwatari, \& Komino, 2019). Management of disaster and/or socio-financial crisis team or department is suggested to focus on identification of the power of the organization engine; the essence (core values) of the business; and, all the resources available and reliable.

The ability of an organization's culture to adapt to the environment's changes and to motivate employees, save the organizational resource, keep it on the market and increase its effectiveness is directly related to the way in which members are aware of the strategic priorities and business plan objectives.

The research concludes that any organization regardless of the industry is better to have a risk management department or a crisis management team in charge with all process of mitigating the risk. Consequently, employees are better to be trained about what does it mean and how to react in case of disaster. Business continuity has to do with keeping the organization running, regardless of the potential risk, threat, natural disasters or cause of power outages; cyberattacks; or epidemiological attacks.

One thing is for sure, disasters and crisis may happen, and it is very difficult to avoid them. We can assess the risk and try to reduce the losses. However, when we talk about a socio-financial crisis, which usually takes time for recuperating, we can prepare a business recovery plan, nevertheless, at the same time, we need to learn to live for a while in this environment's challenge. Putting business on hold, closing, or staying at home is not a long-run solution, it will really affect the socio-financial situation, at all levels, individual, institutional, governmental. We need to take a step back and assess the situation in a critical way, emphasize the core value, the strategic priorities, and bring 
together all resources we can rely on, and more importantly, the people. In a period of crisis, time can become everyone's enemy. Currently, is better to maintain the basis of the business and apply the rule of 5Es, with the accent on strategic priorities and everyone's involvement through a clear operational plan.

\section{REFERENCES}

Bravata, D. M., McDonald, K. M., Smith, W. M., Rydzak, C., Szeto, H., Buckeridge, D. L., \& Owens, D. K. (2004). Systematic review: Surveillance systems for early detection of bioterrorism-related diseases. Annals of Internal Medicine, 140(11), 910-922.Available at: https://doi.org/10.7326/0003-4819-140-11-200406010-00013.

Busick, J. (2014). Disaster recovery. Safety Compliance Letter, 5(2562), 5.

Collier, B. L., \& Babich, V. O. (2019). Financing recovery after disasters: Explaining community credit market responses to severe events. Journal of Risk and Insurance, 86(2), 479-520.Available at: https://doi.org/10.1111/jori.12221.

Dikbiyik, F., Tornatore, M., \& Mukherjee, B. (2014). Minimizing the risk from disaster failures in optical backbone networks. Journal of Lightwave Technology, 32(18), 3175-3183.Available at: https://doi.org/10.1 109/jlt.2014.2334713.

Front Matter, I. o. M. (2007). Hospital-based emergency care: At the breaking point. Washington, DC: The National Academies Press.

Gault, F. (2018). Defining and measuring innovation in all sectors of the economy. Research Policy, 47(3), 617-622.Available at: https://doi.org/10.1016/j.respol.2018.01.007.

Grigsby, J. (2002). Disaster recovery plans-Now more than ever. The Receivables Report, 17(4), 11-12.

Grothmann, T., \& Reusswig, F. (2006). People at risk of flooding: Why some residents take precautionary action while others do not. Natural Hazards, 38(1-2), 101-120.Available at: https://doi.org/10.1007/s1 1069-005-8604-6.

Harnish, V. (2020). Why A one page vision summary is critical for your business growth and how to create your own. Growth Institute. Retrieved from https://blog.growthinstitute.com/scale-up-blueprint/one-page-vision-summary.

Izumi, T., Shaw, R., Djalante, R., Ishiwatari, M., \& Komino, T. (2019). Disaster risk reduction and innovations. Progress in Disaster Science, 2, 1-8.

Jones, G. R. (2013). Organizational theory, design, and change (7th ed., pp. 23-49). Upper Saddle River, NJ: Pearson.

Lindell, M. K., \& Perry, R. W. (2000). Household adjustment to earthquake hazard: A review of research. Environment and Behavior, 32(4), 461-501.Available at: https://doi.org/10.1177/00139160021972621.

Moşteanu, N. R. (2020a). Management of disaster and business continuity in a digital world. International Journal of Management, $11(4), 169-177$.

Moşteanu, N. R. (2020e). Finance digitalization and its impact on labour market. Technium Social Sciences Journal, 8.

Moşteanu, N. R. (2020b). Challenges for organizational structure and design as a result of digitalization and cybersecurity. Paper presented at the Proceedings of 9th International Conference on Business and Economic Development, New York, USA, August 2020.

Moşteanu, N. R., \& Galea, K. (2020). Artificial intelligence and cyber security - face to face with Cyberattack - a Maltese case of risk management approach. Ecoforum Journal, 9(2).

Moşteanu, N. R. (2020c). Artificial intelligence and cyber security - A shield against cyberattack as a risk business management tool - Case of European Countries. Quality-Access to Success Journal, 21(175), 148-156.

Moşteanu, N. R., \& Faccia, A. (2020). Digital systems and new challenges of financial management - FinTech, XBRL, Blockchain and Cryptocurrencies. Quality-Access to Success Journal, 21(174), 159-166.

Moşteanu, N. R. (2020d). Digitalization and Green Economy - changes of business perspectives. Paper presented at the Proceedings of 4th International Conference on Cloud and Big Data Computing, Liverpool, UK, August 2020. 
Nathanial, P., \& Van der Heyden, L. (2020). Crisis management: Framework and principles with applications to CoVid-19.

INSEAD Working Papers Collection, 17, 1-8.Available at: http://dx.doi.org/10.2139/ssrn.3560259.

Parachi, J. (2020). Disaster recovery and Crisis management. Management Study Guide Content Team. Retrieved from: https://www.managementstudyguide.com/disaster-recovery-and-crisis-management.htm.

Rejda, G. E., \& McNamara, M. J. (2017). Principles of risk management and insurance (13th ed., pp. 64). Edinburgh: Pearson.

Slovic, P. (2000). Perception of risk. Series: Earthscan risk in society ser (pp. 280-285): Taylor \& Francis Group.

Slovic, P. (1992). Perception of risk: Reflections on the psychometric paradigm. In: S. Krimsky and Golding D., Ed., Social Theories of Risk (pp. 117-152). Westport, CT: Praeger Publishers.

Smircich, L. (1983). Concepts of culture and organizational analysis. Administrative Science Quarterly, 28(3), 339-358.

UNISDR. (2015). Global assessment report on disaster risk reduction. Retrieved from https://sustainabledevelopment.un.org/index.php?page=view\&type $=400 \& n r=2046 \& \mathrm{menu}=1515$.

Online Science Publishing is not responsible or answerable for any loss, damage or liability, etc. caused in relation to/arising out of the use of the content. Any queries should be directed to the corresponding author of the article. 